\title{
SIMPLIFICATION OF MARKETING SCHEME FOR BUSINESS START-UPS
}

This paper deals with the topic of marketing planning simplification in order to use it for start-ups in the field of small \& medium enterprises. There are 11 main question areas which can be used for logical and empiric marketing approaches. These questions are elaborated on the basis of standard marketing planning methods and approaches from the literature given in references.

Keywords: marketing, marketing planning, simplification, business start-up, marketing management.

\section{Introduction to the topic}

Nowadays development on the markets is strongly focused on new technologies and where they are used. Idea is always the main point but marketing is sometimes left behind. Of course, the product and its parameters are a crucial part of corporate strategy. Without relevant information about market and customers and without funds the idea, no matter how good it is, is doomed to oblivion. Education institutions play an important role in society, should therefore also contribute to the growth of innovation, creative solutions and the increasing competitiveness of the nation [11].

Present markets have also a lot of opportunities for cooperation and partnership, e.g. entrepreneurial and technological incubators, start-up's subvention funds, etc. There are a lot of possibilities how to bring an idea on the market. The problem is often not the lack of opportunities but the lack of information. There are a lot of marketing publications oriented on planning and strategy. These works are often of high quality - their scientific value and the amount of pages are great. Creative people want to work on their ideas only as they are not interested in marketing plans structures and competition analysis methods.

Let us introduce a fictive but realistic example: University is a great environment for new ideas. A few young scientists have made an improvement in technology with high possibility to be successful on the market. Yet the inventors are not interested in marketing. They just want to develop their product. What would they do? They either can offer their idea to the people who have some marketing notion or they can start studying marketing or they just can start using logical and critical thinking and relevant information.

Elaborated marketing structure is a logical construction. It is an approach which enables, by using relevant information and critical stance, to make simple but accurate marketing plans and strategies.

\section{Brief theoretical background}

According to the marketing management literature authors there are some rules bound to the market success $[1,6,8,20]$. One of the main current marketing approaches is customer orientation. Satisfaction of customers is a never-ending process which depends on various factors. Management must define these factors precisely. The main ones are:

- Relevant information about customers which must lead to appropriate segmentation.

- Segmentation must be dynamic - this means that the input information must be also actual and relevant. "Know your customer!" - this has to be one of the most important mottos in the company's vision.

- Quick and appropriate reaction on customers' needs opinions and demands. All this must be recorded and processed by the management information system. To satisfy your customers means that they come back; they will be loyal and spread the loyalty to their social networks.

- Effective use of company's resources in terms of customer's satisfaction. In business there must be always profit. Price of the products must be acceptable for the customers and also profitable for the company.

Other approaches are more oriented to single marketing areas. For example, analysis of competition is focused on a deep study of company's rivals, on their strengths and weaknesses. The main goal of this method is to have actual information about competitors and to know how to be better or different $[2,5,10,14,19]$. Monitoring of relevant environment is a method for gathering significant information $[12,13,14]$. Every business exists in specific

\footnotetext{
* Jakub Soviar

Department of Management Theories, Faculty of Management Science and Informatics, University of Zilina, Slovakia,

E-mail: jakub.soviar@fri.uniza.sk
} 
environment. For example, for a software development company the progress in software technologies is crucial. They have to watch this development and try to use the acquired information. There are, of course, a lot of other analysis methods, e.g. product and portfolio analysis, monitoring of marketing communication effectiveness, balanced scorecard, etc.

\section{Marketing planning for business start-ups}

The following structure is a modification of standard marketing planning structures in terms of simplicity. There are provided 11 questions considering marketing planning. All these questions are logical constructions for basic marketing analysis. This method is intended to be used in small and medium enterprise start-ups, particularly in the field of technological innovations marketing. The application of this method consists in responding to all the questions raised using relevant and significant data.

a) Know your product! Obviously it is not a question. It is a must. Deep knowledge of the product is an essential part of marketing process. The main elements of knowledge about product are: technical and other parameters; production process and transformation processes; production costs; possibilities for savings in productions, e.g. with a higher production, etc.; complexity of a product - warranty, packing, servicing, etc.

b) Who is the customer of this product? It cannot be said that there is a business without selling. If there is no demand for the product, the product is not relevant for the market. One of the marketing methods used for customer analysis is called segmentation. It refers to the arrangement of customers to groups which are homogenous inside and between each other heterogeneous as much as possible. Segmentation is based on the use of segmentation criteria. These are picked in order of their relevance for the case given: economic (e.g. average income), industrial sector (for selecting only the companies from the relevant sector), technology usage level (for some companies technology is more crucial), etc. The primary segment or segments should be specific as much as possible - in b2b there should be specific companies.

c) How, where and when will the customers know about your product? The whole industrial branch nowadays is marketing communication. Mass media are the most expensive ones. Traditional communication channels are overloaded with communication. If I know my primary segment, I can be precise and specific and I can choose media and techniques which are "for optimal price". In some cases it could be just e-mail or event presentation. Content of communication should be adapted for the taste, style and tendencies of target group (primary segment). For example, there is a huge difference between marketing communications of products of the same brand to various segments: cameras for mass consumer segment are advertised on $\mathrm{TV}$, radio and newspapers; cameras for professionals in annual expositions, professional magazines and webzines, etc. It is also necessary to know the sum which could be used for marketing communication. Simple decisions on marketing commu- nication can be performed through answering the following questions: Who do I want to address?; How much money do I have for it?; What do I want to say?; Which techniques will be used?; Which media do I chose?; What will be the time and frequency framework?; What can I handle and what do I need any help with?; What kind of effects can be expected?

d) How will your product reach the customers? We are speaking about distribution, which should have exact parameters. We also speak about the place where the customer meets the product or consumes it (the point of purchase, web pages, etc). In order to ensure the customer's satisfaction it is necessary to reach comfort, security and speed of product delivery. The company's goal should be the same in order to gain payment and also customer's satisfaction.

e) How much will your product cost? Price of the product can be simple set by responding the following question: How much do you have to earn to have a profit? There is crucial to know the production costs. It is not only the production, it could also be energies, rent, licenses, taxes, etc. If there is a profit, it is good to know how to use it (expand, invest, etc). There should be a system of discounts (quantity, closeness of delivery, promptness of payment, the way of payment, reciprocity - barter, etc). It is also good to know the prices of competitors. So, the final price could be set by counting all costs for production with the projected profit.

f) Who are your competitors, what are they good at and why is that so (and vice versa)? We are talking about the substitution your competition is everything that can replace your product by the customer. So, competition is not only homogenous the same or similar products as yours - but also substitution - different products assigned for the same group of consumers. It is necessary to have a deep interest in competition. We can learn from competition. We can find their strong and weak sites and use it in our strategies.

g) Who can be your partner? Currently, partnership and cooperation are considered to be business strategies. It is always possible to use some start-up funding mechanism, incubation, join the cluster or network. These opportunities could raise your competitiveness. In business partnership is always important one question: What benefits can I get and what do I have to offer?

h) What else opportunities, threats or limitations exist on the market where you want to realize yourself? If we are talking about business we must also consider impacts from wider environment. Mostly they are: legislature (civil law, business law, taxes, charges, judicial system, etc); macro-economic stage of market (average salaries, income per capita, willingness to investments, willingness to buy, GDP, GNP, etc); technology, R\&D (availability, access, stage, prices, etc); cultural and social issues; natural environment impacts, etc.

i) What are your business goals? Your goals should reflect the answers to the previous questions. You can set your goals properly after you have relevant information about market. The goals should be set within the S.M.A.R.T. method. This method tells us that every goal must be specific, measurable, attainable, relevant and time-bounded ${ }^{1)}$.

\footnotetext{
${ }^{1)}$ More information to the S.M.A.R.T. method here: http://www.projectsmart.co.uk/smart-goals.html; http://en.wikipedia.org/wiki/SMART_criteria
} 
j) What are your plans and strategies for reaching your goals? In terms of simplification here you can just work out your approaches for reaching your goals. There are a lot of methods in the field of strategic management and marketing literature you can use. To do it simple follow these rules:

- Logical structure. Allocate main processes and connect them in order to achieve your goals.

- Time limitations. Every process should be performed in delimitated time.

- Setting of competencies.

- Setting of budget or expenses.

- Use of visualization - e.g. Gantt charts, etc.

k) Control! We have started with the command and finish also with another one. When all plans are made you are ready to launch them on the market. When you have set your plans and strategies into logical processes you will be able to control them. Just mark the main points or parts of your plan and control if the reality responds to the project. If there are any differences you can learn about the reasons and make corrections.

\section{Conclusion}

It is always good to know the successful marketing conceptions. All the questions are elaborated from the main planning approaches and case studies of successful start-ups. To use these questions for planning of marketing process it is necessary to be critical - critical in the way of approach. Answers of single questions should be precise and accurate. There should be used arguments and facts. All data used for answering must be relevant and actual. Simplification doesn't mean easiness. Questions and approach are simple for understanding - for performing it is a quite hard work. There are a few recommendations for improving marketing planning:

- Consult with people who are relevant or have relevant information and are accessible.

- Be critical to your projects.

- Use information and criticism to your advantage.

- Be interested in the market about all relevant events and information.

- Watch the competitors.

- Listen to your customers and potential customers.

\section{References}

[1] BAINES, P.: Marketing. Oxford University Press, 2008.

[2] BOUCKOVA, M.: Marketing. C. H. Beck, 2004.

[3] HANZELKOVA, A., KERKOVSKY, M., ODEHNALOVA, D., VYKYPEL, O.: Strategic Marketing. Theory for Praxis (in Czech). C. H. Beck, 2009.

[4] KERIN, R., PETERSON, R.: Strategic Marketing Problems. Cases and Comments. Pearson, 2009.

[5] KITA, J.: Marketing. IURA EDITION. Bratislava, 2010.

[6] KOTLER, P., ARMSTRONG, G.: Marketing. Prague, 2006.

[7] KOTLER, P., CASLIONE, J. A. Chaotics: The Business of Managing and Marketing in the Age of Turbulence (in Czech). Prague, Computer Press, 2009.

[8] KOTLER, P., JAIN, D. C., MAESINCEE, S.: Marketing Moves (in Czech). Management Press. Prague, 2007.

[9] KOTLER, P., KELLER, K. L.: Marketing Management. Prague, Grada, 2007.

[10] KUMAR, N. Marketing as Strategy (in Czech). Prague, Grada, 2008.

[11] LENDEL, V., KUBINA, M.: Cooperation of Enterprises and Universities within Clusters (in Slovak). In: Cooperation of enterprises and universities in the area of marketing II (in Czech). Liberec: TU in Liberec, pp. 39-46, 2008.

[12] PORTER, M.: Competitive Advantage (in Czech). Victoria Publishing, Prague, 1994.

[13] PORTER, M.: On Competition. Boston, Harvard Business School, 1998.

[14] ROBBINS, P, S., COULTER, M.: Management. Prague, Grada, 2004.

[15] SOlOMON, M. R., MARSHALL, G. W., STUART, E. W.: Marketing: Real People, Real Choices (in Czech), Computer Press, Prague, 2006.

[16] SOVIAR, J.: Event Marketing. In Trends of marketing communication (in Slovak). European Polytechnic Institute, Kunovice, pp. 45-58, 2009.

[17] SOVIAR, J.: Marketing in Cluster - benefits of "Shared" Marketing (in Slovak). In University as facilitator of society and regional development 2009 (in Czech). European Polytechnic Institute, Kunovice, pp. 253-258, 2009.

[18] SOVIAR, J.: Principles of Formal Organization. In Intern. conference TRANSCOM 2007. University of Zilina, pp. 119-122, 2007.

[19] STRISS, J., VODAK, J., KUBINA, M., JANKAL, R., SOVIAR, J.: Marketing Management (in Slovak). University of Zilina, 2009.

[20] TROMMSDORFF, V., STEINHOFF, F.: Marketing of Innovations (in Czech). C. H. Beck, 2009. 